\title{
Seasonal variation in thyroid activity of turtle Lissemys punctata with respect to annual cycle of reproduction
}

\author{
Vidya R. Chandavar ${ }^{2}$ and Prakash R. Naik ${ }^{1}$ \\ ${ }^{1}$ Endocrinology Laboratory, Department of Studies in Zoology, University of Mysore, Manasagangorti, Mysore - \\ 570006, INDIA \\ ${ }^{2}$ Yuvaraja's College, University of Mysore, Mysore- 570005, INDIA \\ ${ }^{2}$ Corresponding author. E-mail: vidyachandavar@yahoo.co.uk
}

\begin{abstract}
The objective of the present investigation was to study the relationship between thyroid activity and reproductive cycle in turtle Lissemys punctata. The animals were studied in the annual seasonal cycle of reproduction for two consecutive years, which is distinguished into three separate periods namely regenerative, reproductive and recrudescent. The thyroid in L. punctata was observed to be a single pyramid shaped gland, creamy white to reddish-brown in color with lenticular profile. The diameter of the follicle was lowest in regenerative period, which gradually increased in reproductive period attaining maximum size in recrudescent, where as epithelial height was highest in regenerative period, which gradually decreased in reproductive period reaching minimum in recrudescent period. Thyroid activity varies annually in relation to different phases of reproductive periods.
\end{abstract}

Keywords: Plasma glucose, Season, Thyroid, Turtle

\section{INTRODUCTION}

Thyroid gland is composed of many spheroid structures called thyroid follicles, in which thyrocytes are integrated in their specific structural and functional polarization (Toda et al., 2001). The histological appearance of the thyroid gland, follicular cell-height, nature of colloid and its relative weight showed a seasonal variation and cyclic activity, correlated with the active and inactive phases of reproduction in U romastix hardwickii (Sinha and Choubey, 1981). The ability of plasma to bind thyroxine (T4) was examined by radioimmunoassay, in relation to variations in thyroidal state associated with age, sex, environment in Pseudemys scripta (Licht et al.,1990). Chow et al. (1990) studied relation between $\mathrm{pH}$ regulation and iodide transport in the thyroid glands of turtle. Machado et al. (1991) investigated the action of insulin on the uptake of glucose and alpha-aminoisobutyric acid in vitro thyroid glands in turtle Chrysemys dorbigni. Thyroid hormone metabolism by 5 '-monodeiodinase was characterized in peripheral tissues of Trachemys scripta and compared with that of rat (Hugenberger and Licht, 1999). Seasonal changes in thyroid function in the desert tortoise $\mathrm{G}$ opherus agassizii, exhibited distinct cycles in both sexes. Elevated thyroxine is associated with periods of increased feeding and reproductive activity (Kohel et al., 2001).

Reptiles exhibit variation in thyroid activity with respect to surrounding temperature, reproductive cycle, physiological activity etc. All these have effect on total metabolism of an organism particularly in poikilotherms (Lynn, 1970). The Soft-shelled terrapin or flap-shell turtle, Lissemys punctata is mainly found in the lowlands but also occupies some water bodies in the hills. When disturbed it hides under mud and among aquatic vegetation. They are omnivorous, non aggressive turtles belonging to family Trionychidae. They adapt to a variety of environments and hibernate during winter, by burring into the loose soil. After they emerge from hibernation, they feed on waterweeds and soon change over to being carnivore feeding on insects like mosquito (Das, 1995). Objective of the present investigation was to study the relationship between thyroid activity and reproductive cycle in the turtle L. punctata.

\section{MATERIALS AND METHODS}

Adults animals of $L$. punctata of both sexes weighing 900 to $2400 \mathrm{~g}$ were collected from Kabini backwaters near

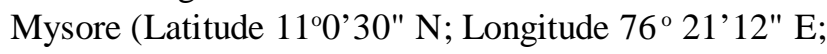
catchment area $2142 \mathrm{Sq} . \mathrm{km}$ ) and were housed in outdoor enclosure having cement cistern containing water and sand. The cistern measured $7 \times 5 \times 5 \mathrm{ft}$ with a slope on one side from the bottom for enabling the animal to come on land. They were fed fresh carrot and spinach ad libitum. Since they are omnivorous they might have also eaten insects. The ambient temperature of Mysore varied between $11-37^{\circ} \mathrm{C}$. The sex ratio is $1: 1$ (Das, 1995). The animals were studied in the annual seasonal cycle of 
reproduction for two consecutive years which is distinguished into three separate periods namely regenerative, reproductive and recrudescent. Different periods of reproductive cycles were assigned by careful observation of the status of the gonad during two successive cycles of reproduction. Four adults of both the sexes were studied in each period. "Guidelines for Care and Use of Animals in Scientific Research" were followed (Anonymous, 2000). The animals were injected with sodium pentobarbital $(50 \mathrm{mg} / \mathrm{kg}$ b.w.) intra-peritoneal for recording their body length and weight and were sacrificed.

Thyroid histochemisrty: The thyroid glands from the animals of all the periods were removed, weighed and fixed in Bouin's fluid. Paraffin embedded tissues were sectioned at $10 \mu$. Bromophenol blue method was followed for histochemical localization of thyroglobulin/ colloid. Measurements of follicles, follicular epithelial height and gap between the colloid and follicular epithelium were made by software Image pro express, version 5.1.

L iver histochemisrty: Meanwhile liver samples from all the animals were fixed in Rossman's fixative, sectioned at 9-10 $\mu$ and processed for localization of glycogen by Periodic Acid Schiff (PAS) technique (Hotchkiss, 1968). The PAS positive mass localized in the cytoplasm was taken into consideration for qualitative analysis of glycogen.

Plasma glucose: Simultaneously, blood samples from carotid artery were collected and centrifuged at $4{ }^{\circ} \mathrm{C}$ at $10,000 \mathrm{rpm}$ for 10 minutes. The separated serum was immediately used for estimation of glucose by enzyme glucose oxidase method of Trinder (1969). Plasma glucose $(\mathrm{mg} / \mathrm{dl})$ was determined by averaging the values of multiple samples of four $(4 \times 10)$ animals in every season. The averaged values represent order of magnitude rather than fixed levels, as the range of variability is great between individuals of this population.

Statistical analysis: The measurements were expressed as mean \pm SD for follicular diameter; epithelial height; gap between colloid and follicular epithelium in microns $(\mu)$ and plasma glucose level in $\mathrm{mg} / \mathrm{dl}$ during different periods was carried out using analysis of variance (ANOVA). Wherever the ANOVA values $(F)$ were found to be significant, Duncan's Multiple Range Test (DMRT) was applied. The $P$ value $<0.05$ was considered significant.

\section{RESULTS}

The thyroid in L. punctata is a single pyramid shaped gland, creamy white to reddish-brown in color, with lenticular profile. It is present on the right side in the neck region just anterior to heart. On an average it measured 7-9 $\mathrm{mm}$ in length. The gland was enclosed in a connective tissue capsule (fibrous sheath); the septa can sometimes be traced into the gland dividing it into illdefined lobules. The gland consists of many follicles; each follicle is lined by a single layer of epithelial cells placed on a basement membrane.

R egener ative period: Initiation of gonad activity occurs in this period. The period fall between March to June and corresponded with summer season, the temperature varied from maximum $35^{\circ} \mathrm{C}$ and minimum $19^{\circ} \mathrm{C}$. They were active during these days and become voracious eaters to gain body weight. Animals weighed moderate and the weight of the thyroid was minimum (Table 1). Thyroid revealed lowest follicular diameter with maximum epithelial height. The gap between the colloid and epithelium also stood high (Table 1). The epithelium was continuous in all follicles (Fig.1 and 1a). The plasma glucose and PAS positive glycogen masses in liver were moderate. But the abdominal fat was least (Table 1).

Reproductive period: The peak of gonad activity appeared in this period which falls between July to August. The temperature ranged from $28^{\circ} \mathrm{C}$ maximum to minimum of $19^{\circ} \mathrm{C}$, these are the months of monsoon. The females showed the presence of mature ova in the ovary and developing eggs in the oviduct earlier than July. They started laying eggs in clutches by the end of August and continued till October. In males the testes attained its largest size only between July and August after which it regressed very soon. Mating occurred in this period. The thyroid weighed moderate, the diameter of the follicle and epithelial height also measured moderate with prominent continuous epithelium (Table 1). The chromophobe droplets were seen in the colloid at the periphery (Fig. 2 and 2a). The plasma glucose of this period reached highest value. Liver samples showed minimum PAS positive mass and abdominal fat was moderate (Table 1).

R ecrudescent period: The gonads in both sexes were at degenerative state between Sept-Feb, ultimately resulting in the loss of reproductive ability. The temperature was maximum $28^{\circ} \mathrm{C}$ and minimum $11^{\circ} \mathrm{C}$. L. punctata gradually stopped feeding and hide in the loose soil. The thyroid weighed highest of all the periods. The gland appeared more spongy, translucent and lenticular. The diameter of the follicle was highest of all the periods. The epithelium found discontinuous with minimum height in this period and the colloid contents were without chromophobe droplets at the periphery (Fig. 3 and 3a). There was maximum abdominal fat and liver glycogen and minimum plasma glucose (Table 1).

\section{DISCUSSION}

There is no significant variation in weight of the animal between periods. Weight of the thyroid and diameter of the follicle gradually increased from regenerative to reproductive period attaining the highest values in recrudescent period due to accumulation of colloid. 
Table 1. Morphometric measurements of $L$. punctata during annual cycle of reproduction.

\begin{tabular}{llll}
\hline & $\begin{array}{l}\text { Regenerative } \\
\text { March-J une }\end{array}$ & $\begin{array}{l}\text { Reproductive } \\
\text { J uly-Aug }\end{array}$ & $\begin{array}{l}\text { Recrudescent } \\
\text { Sept-F eb }\end{array}$ \\
\hline Season & Summer & Monsoon & Winter \\
Animal weight $(\mathrm{g})$ & $1460 \pm 432^{\mathrm{a}}$ & $1560 \pm 424^{\mathrm{a}}$ & $1390 \pm 284.6^{\mathrm{a}}$ \\
Thyroid weight $(\mathrm{g})$ & $0.125 \pm 0.06^{\mathrm{a}}$ & $0.208 \pm 0.2^{\mathrm{b}}$ & $0.233 \pm 0.13^{\mathrm{c}}$ \\
Diameter of the follicle $(\mu \mathrm{m})$ & $232 \pm 30^{\mathrm{a}}$ & $244 \pm 26^{\mathrm{a}}$ & $462 \pm 52^{\mathrm{b}}$ \\
Epithelial height $(\mu \mathrm{m})$ & $22 \pm 0.5^{\mathrm{c}}$ & $15 \pm 1.2^{\mathrm{b}}$ & $10 \pm 0.4^{\mathrm{a}}$ \\
The gap $(\mu \mathrm{m})$ & $43 \pm 5^{\mathrm{c}}$ & $13 \pm 2^{\mathrm{a}}$ & $39 \pm 1.2^{\mathrm{b}}$ \\
Plasma glucose $(\mathrm{mg} \%)$ & $96.87 \pm 3.63^{\mathrm{b}}$ & $119.27 \pm 1.68^{\mathrm{c}}$ & $91.39 \pm 2.76^{\mathrm{a}}$ \\
Liver glycogen & ++ & + & +++ \\
Abdominal fat & + & ++ & +++ \\
\hline
\end{tabular}

Note: Mean with same letters is not significantly different from each other; $+++=$ Maximum; $++=$ Moderate; $+=$ Minimum

Where as epithelial height was maximum in regenerative period which significantly reduced in reproductive period reaching minimum in recrudescent period. Under histochemical study thyroid follicles appeared smaller with tall columnar epithelium indicating its active stage for synthesis of thyroglobulin in regenerative period. Active follicles have tall columnar cells with little stored colloid. As the colloid storage increased at the end of recrudescent period the follicular epithelium become thin, discontinuous and inactive. Thyroid of (Trachydosaurus rugosus, Chelodina longicollis and Crocodylus johnstoni) the reptiles were found to be active at high temperatures (Hulbert and Williams, 1988). L. punctata exhibits moderate value for plasma glucose during regenerative period though it was voracious eater. Consumption of more food and the moderate value of plasma glucose indicate steady rise in its metabolism. Initiation of thyroid activity utilized the glucose by the peripheral tissues. Part of glucose might have been stored in the form of glycogen as a reserve food material as indicated by moderate amount of glycogen mass in the liver (Table 1) as energy reserve needed for the next reproductive period. Increased thyroid activity stimulates fat mobilization of regenerative period in $L$. punctata. Elevated T (4) in desert tortoises is associated with periods of increased feeding and reproductive activity, supporting a role for thyroid hormones in these energy-demanding activities (Kohel et al., 2001). The regenerative period is a preparative stage for forthcoming reproductive period. Thyroid function in poikilotherms has been associated with phases of metabolism and glycogen changes particularly in liver (Table 1). L. punctata, during regenerative period exhibit hyper thyroid activity by having chromophobe droplets at the periphery of the colloid.

The morphometric measurements of thyroid indicate that weight of the thyroid gland is dependent on colloid content rather than weight of the animal. Different tissues have different, temperature-independent, annual rhythms of sensitivity to thyroxin (Gupta and Thapliyal, 1985). The plasma glucose showed its highest value in reproductive period as the animals continued feeding and remained active. Since active thyroids increase basal metabolic rate (BMR), glucose increased in the plasma. The turtle L. punctata instinctively stop eating on their own prior to hibernation during recrudescent period, when the temperature was low. During hibernation they become less active like non-feeding, sluggish etc., animals loose body weight. They do not even bask to gain body temperature; instead hide into the loose soil. Recrudescent period corresponds with winter season; during this adverse condition, stored colloid may maintain BMR. Animals of this species exhibit last stage of thyroid activity having brittle colloid bound with very thin epithelium often ragged. In female soft-shelled turtle, Lissemys p. punctata thyroid gland weight and epithelial height were higher during March through May, decreased from June through August and began to rise thereafter (September through February) (Sengupta et al., 2004). In the present investigation the thyroid weight and epithelial height are inversely related. In males the regression of the reproductive system begins earlier when compared to female reproductive system. At autopsy females contained mature eggs in the oviduct. The live animals even laid eggs until the end of October. It appears that the brittle colloid nature is related to regression of reproductive system. Hence, in male specimens of $L$. punctata the colloidal appeared brittle with 

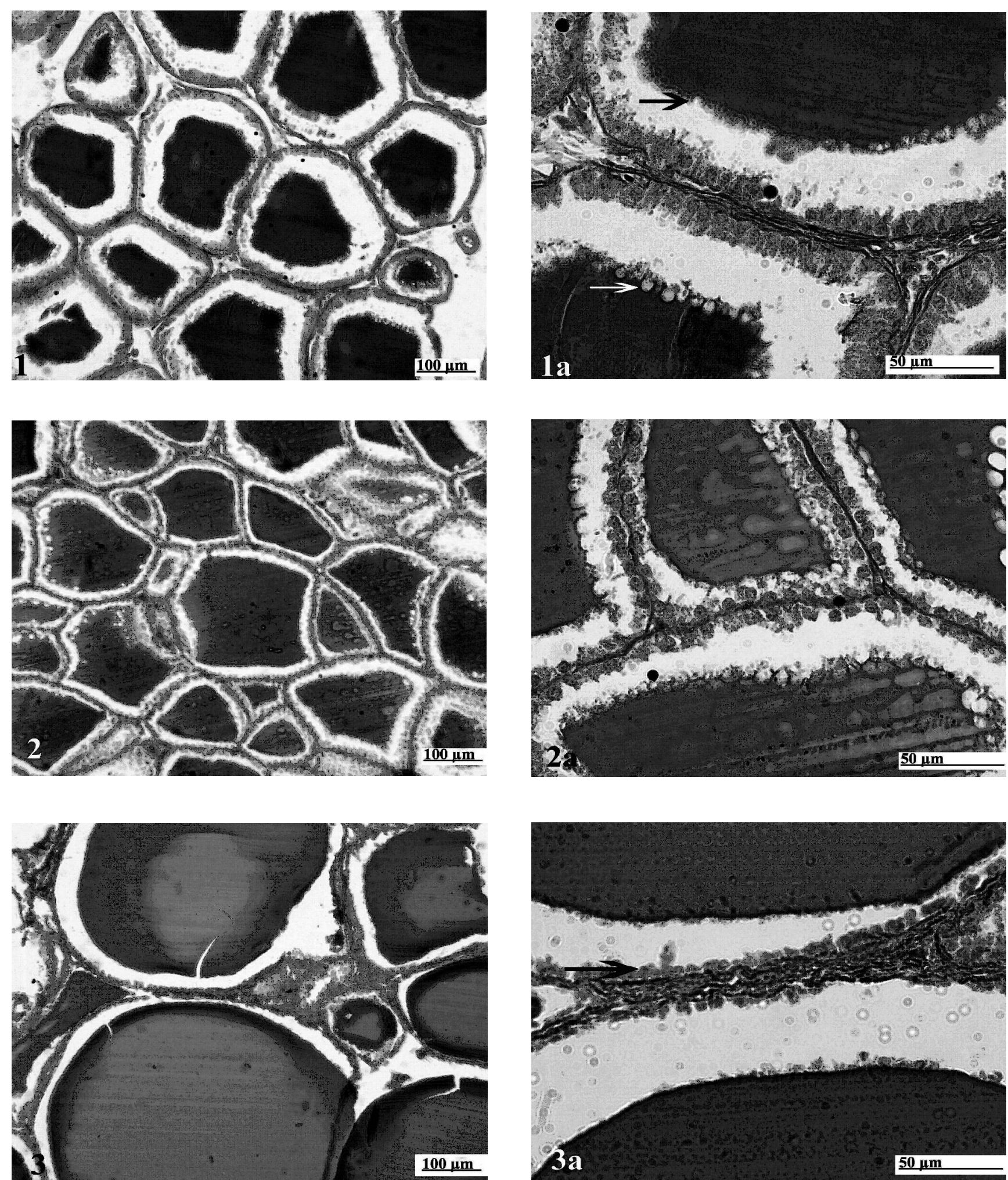

Figs.1-3: Thyroid sections of $L$. punctata showing variation in follicle size, epithelial height and nature of colloid in annual seasonal cycle of reproduction. 1) Regenerative period: Note darkly stained colloid with wide gap between colloid and follicular epithelium. x10. 1a.) Partial section of regenerative period: Showing chromophobe droplets (arrows) at peripheries and columnar cells (solid dot) on basement membrane. Note the vascularization at the corners of the follicles. $x 40$. 2.) Reproductive period: Note increased colloid content and decreased gap between colloid and follicular epithelium. x10. 2a). Partial section of reproductive period: M any chromophobe droplets at peripheries (solid dot) with comparatively lesser epithelial height. $x 40.3$.) Recrudescent period. Note increased follicle size with round shape and ragged follicular epithelium. x 10. 3a.) Partial section of recrudescent period: Showing thin squamous epithelium (arrow) and smooth colloid margin. $x 40$.N ote: The photographs are the representatives of each period. 
discontinuous epithelium much earlier than in female thyroids. As fall and winter arrive and the days grow shorter, L. punctata began to slow down activity probably corresponded with drop in body temperature and metabolism as it is more beneficial to save energy. The energy was saved in the form of abdominal fat, since turtles can only store fat in the abdominal cavity. Healthy specimens deposit fat stores in preparation for hibernation. If not allowed to hibernate, these animals may be at risk for obesity. Hibernation is believed to be necessary for the normal functioning of the thyroid gland. There is also evidence that hibernation helps to maintain the immune system. The animals burrow deep in leaf litter or soft earth, which insulates them from temperature changes, as the days lengthen and temperatures rise, they emerge in the spring (Morris, 2003).

In both regenerative and reproductive period unlike recrudescent period the colloid showed many pinocytic vesicles (Fig. 1a and 2a) at the periphery as chromophobe droplets indicate the release and re-absorption of thyroglobulin from the follicular epithelium. The thyroid gland and follicular epithelial cell-height, its relative weight showed a seasonal variation and cyclic activity. Thyroid activity found to be more in summer than in winter and also correlated with the active and inactive stages of annual seasonal cycle of reproduction in $L$. punctata as was reported in U romastix hardwickii (Sinha and Choubey, 1981). In the month/s of May/June, when the environmental temperature was high the thyroid appeared to be most active, while in December/January, when the environmental temperature fall the follicles had a greater volume due to accumulation of colloid, as the epithelial cells stopped secretion, they become thin. The parameters like thyroid weight, epithelial height moderately increased during the progressive phase, maximally increased during breeding, decreased in the regression phase and decreased further during the non-breeding phase in both sexes of $D$ endrocitta vagabunda (Chaudhuri and Maiti, 1996). Thyroid is known to increase body heat production; since this heat production may not be enough in L. punctata during recrudescent period therefore it gains or conserves body heat by hiding in the soil.

In the present investigation, the thyroid gland of $L$. punctata weighed between $0.120 \mathrm{~g}$ to $0.246 \mathrm{~g}$. The follicle diameter measured from $200 \mu$ to $500 \mu$. Inactive follicles of recrudescent period appeared round when compared to that of other two periods. The simple epithelium of the follicle varied in height from columnar to squamous depending upon the functional state of the follicle. Thyroid weight and diameter of the follicle showed positive correlation. Weight of the gland is dependent on the amount of the colloid present in follicular lumen.

\section{Conclusion}

All these annotations indicate that thyroid activity varies annually. It decreases from regenerative to reproductive and recrudescent period. Thyroid weigh maximum due to accumulation of colloid. Spongy texture and translucent appearance depend on quantity of colloid/thyroglobulin in the follicles. At the time of recrudescent period $L$. punctata stores energy in the form of abdominal fat and liver glycogen.

\section{ACKNOW LEDGEMENTS}

The first author acknowledges the University of Mysore for the award of Teacher Fellowship.

\section{REFERENCES}

Anonymous (2000). Guidelines for care and use of animals in scientific research. New Delhi: Indian National Science Academy.

Chaudhuri, S. and Maiti, B.R. (1996). Changes in thyroid activity during the annual sexual cycle of a wild avian species, the tree pie Dendrocitta vagabunda. European J ournal of M orphology, 34(4):321-324.

Chow, S.Y., Woodbury, D.M. and Yen-Chow, Y.C. (1990). Relation between $\mathrm{pH}$ regulation and iodide transport in turtle thyroid glands. J ournal of Endocrinology, 127(1):85-101.

Das, I. (1995). Turtles and tortoises of India. World Wide Fund for Nature-India. Bombay, Delhi: Oxford University Press.

Gupta, B.B. and Thapliyal, J.P. (1985). Role of thyroid and testicular hormones in the oxidative metabolism of the Indian garden lizard, Calotes ver sicolor. General and Comparative Endocrinology, 58:20-7.

Hotchkiss, R.D. (1968). The Periodic Acid Schiff (PAS) Technique. In: A.G.E. Pearse (Ed.), Histochemistry theoretical and Applied (pp. 659-660), Edinburgh:Churchhill Living stone.

Hugenberger, J.L. and Licht, P. (1999). Characterization of thyroid hormone 5'-monodeiodinase activity in the turtle (Trachemys scripta). General and Comparative Endocrinology, 3(3):343-59.

Hulbert, A.J. and Williams, C.A. (1988). Thyroid function in a lizard, a tortoise and a crocodile, compared with mammals. Comparative Biochemistry and Physiology- PartA, 90(1):41-8.

Kohel, K.A., MacKenzie, D.S., Rostal, D.C., Grumbles, J.S. and Lance, V.A. (2001). Seasonality in plasma thyroxine in the desert tortoise, Gopherus agassizii. General and Comparative Endocrinology,121(2):214-22.

Licht, P., Denver, R.J. and Stamper, D.L. (1990). Relation of plasma thyroxine binding to thyroidal activity and determination of thyroxine binding proteins in a turtle, Pseudemys scripta. General and Comparative Endocrinology, 80(2):238-56.

Lynn, W. G. (1970). The thyroid. In: C. Gans and T. S. Parsons (Eds), Biology of the reptilian (pp 201-234), London, New York: Academic Press.

Machado, V.L., Wassermann, G.F. and Marques, M. (1991). In vitro effect of insulin on the uptake of glucose and alphaaminoisobutyric acid in the thyroid gland of the turtle (Chrysemys dorbigni). General and Comparative Endocrinology, 82(1):8-13.

Morris, Paula (2003). World chelonian trust website www.chelonia.org. 
Sengupta, A., Sarkar, S., Chaudhuri, S.S., Prajna, P.R. and Maiti, B.R. (2004). Seasonal thyroid cycle of the soft-shelled turtle, Lissemys p. punctata (Bonnoterre). Biological Rhythm Research, 35:205-212.

Sinha, A.K. and Choubey, B.J. (1981). Seasonal changes in the thyroid gland of Indian spiny tailed, sand lizard, U romastix hardwickii (Gray) male. Zell forsch M ikrosk A natomy Forsch, 95(1):72-80.
Toda, S., Koike, N. and Sugihara, H. (2001). Cellular integration of thyrocytes and thyroid folliculogenesis: a perspective for thyroid tissue regeneration and engineering. Endocrine J ournal, 48:407-425.

Trinder, P. (1969). Determination of blood glucose using oxidase peroxidase system with a non carcinogenic chromogen. J ournal of Clinical Pathology, 22:158-161. 